\title{
KOMUNIKASI ORGANISASI BERBASIS ELEKTRONIK
}

\author{
Oleh: Muhammad Anshar Akil \\ Fakultas Dakwah dan Komunikasi \\ UIN Alauddin Makassar
}

\begin{abstract}
:
Humans are organizational beings. Since entering the world, a person is always in the organization. Either the smallest organization such as family or Neighborhood Association (RT) until the greatest of organization is countries. Organization is a medium-to-life interdependence of goals. In order for the organization to run effectively it is necessary. Organizational communication can be either vertical or horizontal communication. In the current era of communication and information technology, every organization is required to use electronic technology. The electronic technology, both hardware, software, and networking, help organization can be more effective and efficient in achieving its goals. In addition, through electronic networks, the organization can serve the public without being limited by time and place, so that organizational goals can be more easily realized.
\end{abstract}

\section{Keywords:}

\section{Organization, vertical and horizontal communication, electronic technology}

\section{PENDAHULUAN}

MANUSIA tidak hanya dikenal sebagai makhluk sosial yang hidup berkelompok tapi juga makhluk organisasi - yaitu makhluk yang senantiasa terlibat dalam organisasi. Sejak lahir hingga meninggal dunia, setiap manusia selalu berada dalam organisasi. Mulai dari organisasi yang paling sederhana seperti keluarga, rukun tetangga (RT), rukun warga (RW), dan seterusnya sampai kepada organisasi yang paling besar yaitu negara. ${ }^{1}$

Menurut Harris and Nelson (2008), Organisasi adalah kesatuan hidup yang dinamis, dimana orang-orang bersama-sama menyelesaikan berbagai tujuan ---- mereka berorientasi pada tujuan (Organizations are dynamic, living entities that have been put together to accomplish some type of purpose - they are goal oriented). Agar komunikasi berjalan efektif maka dibutuhkan komunikasi efektif. Dari sinilah pentingnya komunikasi organisasi (organizational communication) dalam menggerakkan segenap sumberdaya yang dimiliki untuk mencapai tujuan organisasi. Komunikasi organisasi itu mencakup kegiatan komunikasi di dalam organisasi (intra-organizational) dan komunikasi antara satu organisasi dengan organisasi lain (inter-organizational). ${ }^{2}$

Komunikasi organisasi berbeda dengan komunikasi kelompok, utamanya sifat komunikasi organisasi yang lebih formal, terstruktur, dan mengutamakan prinsip-prinsip efisiensi dalam kegiatan komunikasinya. Misalnya pertemuan antardireksi perusahaan A 
dengan para manajernya; surat menyurat antara perusahaan A dengan perusahaan $\mathrm{B}$; atau pertemuan antara pimpinan perusahaan A dengan Departemen B. ${ }^{3}$

Jika komunikasi kelompok (groups) lebih bersifat fungsional, maka sebuah komunikasi organisasi bersifat struktural, resmi, diikat dengan aturan-aturan, serta memiliki reward and punishment (penghargaan dan sanksi) bagi anggotanya. Komunikasi organisasi terjadi kapan pun, minimal satu orang yang menduduki suatu jabatan dan anggotanya di dalam suatu organisasi. Fokus komunikasi organisasi adalah komunikasi yang terjadi di antara anggota-anggota suatu organisasi dan menganalisis interaksi yang terjadi di dalam organisasi secara simultan. Sistem komunikasi organisasi cukup rumit, karena menyangkut pertukaran pesan diantara puluhan bahkan ratusan individu yang memiliki tugas dan tanggung jawab berbeda dalam organisasi; dimana pikiran, keputusan, dan perilakunya diatur oleh kebijakankebijakan, regulasi, dan etika; komunikasi organisasi merupakan strategi mengelola dan memimpin organisasi yang dimotivasi oleh kemungkinan-kemungkinan yang berbeda; yang berada pada tahap perkembangan berlainan dalam berbagai kelompok; yang mempersepsi iklim komunikasi berbeda; yang mempunyai tingkat kepuasan berbeda dan tingkat kecukupan informasi yang berbeda pula; yang lebih menyukai dan menggunakan jenis, bentuk, dan metode komunikasi yang berbeda dalam jaringan yang berbeda; yang mempunyai tingkat ketelitian pesan yang berlainan; dan yang membutuhkan penggunaan tingkat materi dan energi yang berbeda untuk berkomunikasi efektif. Interaksi diantara semua faktor tersebut, dan mungkin lebih banyak lagi, kita sebut sistem komunikasi organisasi. ${ }^{4}$

\section{PEMBAHASAN}

\section{Komunikasi Intra dan Inter-organisasi}

Komunikasi organisasi (Organizational communication) dapat didefinisikan sebagai proses pertukaran pesan antara komunikator dan komunikan di dalam sebuah organisasi atau antar organisasi; sebagai cara untuk menjalankan fungsi-fungsi organisasi; untuk mencapai tujuan organisasi secara efektif dan efisien. Komunikasi organiasi juga berarti proses penciptaan dan penafsiran pesan diantara unit-unit komunikasi yang merupakan bagian dari suatu organisasi. Suatu organisasi terdiri dari unit-unit yang berhubungan secara khirarkis antara satu dengan lainnya dan berfungsi sebagai satu sistem dalam mewujudkan tujuan organisasi. Alur komunikasi organisasi mengikuti struktur dalam organisasi tersebut; baik dari atasan ke bawahan; bawahan ke atasan; maupun antara sesama staf organisasi tersebut (Lihat: Gambar 1). 


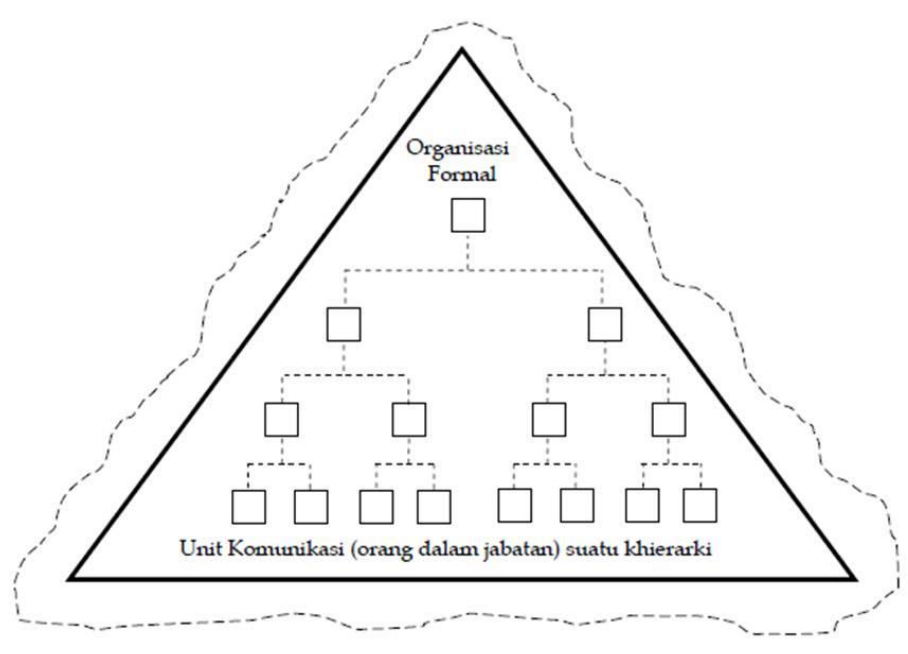

Sumber: Pace \& Faules (1998) dalam Akil (2012: 119)

Gambar di atas menunjukkan konsep suatu sistem komunikasi organisasi. Garis yang terputus-putus melukiskan gagasan bahwa hubungan-hubunga ditentukan alih-alih bersifat alami; hubungan-hubungan itu juga menunjukkan bahwa struktur suatu organisasi bersifat luwes dan mungkin berubah sebagai respon terhadap kekuatan-kekuatan lingkungan yang internal juga eksternal. Meskipun demikian, hubungan antara jabatan-jabatan berubah secara resmi hanya berdasarkan pernyataan pejabat-pejabat organisasi. ${ }^{5}$

Komunikasi organisasi (organizational communication) meliputi komunikasi intraorganisasi (intenal) dan komunikasi inter-organisasi (eksternal). Komunikasi intraorganisasi merupakan aktivitas komunikasi yang terjadi di dalam organisasi, baik komunikasi antara pimpinan dengan staf (vertikal), antara pimpinan dengan pimpinan (horizontal), antara satu bagia dengan bagian lain (cross-sectional) atau antara staf dengan staf (horizontal) di dalam organisasi tersebut. Komunikasi antar-organisasi adalah komunikasi dengan lingkungan luar yaitu aktivitas komunikasi antara suatu organisasi dengan organisasi lainnya, misalnya komunikasi antara organisasi A dengan B, organisasi swasta dengan instansi pemerintah, atau antara suatu instansi dengan instansi lainnya. Komunikasi antar-organisasi bersifat horizontal jika organisasi yang melakukan aktivitas komunikasi bersifat independen antara satu dengan lainnya, kedudukannya setara, dan saling membutuhkan antara satu dengan lainnya. Sedangkan komunikasi antar-organisasi bersifat vertikal bila organisasi yang berkomunikasi bersifat struktural, seperti komunikasi antara kantor pusat dengan cabang, komunikasi antara pemerintah pusat dengan pemerintah provinsi, kedudukan organisasi yang satu dengan lainnya memiliki khirarki baik sebagai up-link (atasan) maupun down-link 
(bawahan). Komunikasi vertikal seperti ini, di satu sisi bersifat komunikasi antar-organisasi dan di sisi lain bersifat komunikasi intra-organisasi, karena organisasi-organisasi yang terlibat komunikasi masih berada dalam satu group organisasi. ${ }^{6}$

Selain itu, agar organisasi bisa tumbuh dan berkembang, kebanyakan organisasi berinteraksi dengan lingkungan luar mereka. Oganisasi-organisasi melakukan hal tersebut dengan jalan bertukar informasi dengan pihak-pihak lain, termasuk menyerap sumberdaya dari luar serta menyediakan barang dan jasa untuk kepentingan lingkungan. ${ }^{7}$

Dalam perspektif komunikasi organiasi, sebuah organisasi dapat diibaratkan sebagai sebuah sistem pemrosesan informasi (information processing systems) yang memiliki faktor input, proses dan output. Dalam organisasi tersebut, setiap bagian melakukan berkomunikasi antara satu dengan lainnya yaitu: mengirim, menerima, dan menyimpan informasi. Para anggota anggota juga belajar memahami pesan, menginterpretasi, memodifikasi, dan mempraktekkannya. Proses komunikasi terus berlangsung selama perusahaan itu masih menjalankan aktivitasnya; sehingga komunikasi organisasi sangat penting dalam menjaga pertumbuhan dan perkembangan sebuah organisasi.

Barnard (1938), mengatakan bahwa "dalam teori organisasi, komunikasi memiliki berada di posisi sentral, sebab struktur, pengembangan, dan ruang lingkup organisasi pada umumnya ditentukan oleh teknik-teknik komunikasi”. Pendekatan ini pada hakekatnya menempatkan komunikasi sebagai jantung organisasi. Proses komunikasi di dalam organisasi berisi elemen-elemen yang kuat secara organisasional dan individual. Pada level individu, perhatikan contoh sederhana di dalam ruangan ujian. Jika tidak ada perbedaan individu dalam pemahaman dan penafsiran, setiap orang akan memberikan jawaban yang sama terhadap soalsoal essay. Namun hal ini tidak akan terjadi, karena setiap mahasiswa dan fakultas mengetahui bahwa input organisasional ke dalam proses komunikasi sesuai dengan struktur saluran komunikasi dan kedudukan dari orang yang menerimanya. Posisi organisasional secara kuat mempengaruhi interpretasi komuniksi dari setiap individu. Struktur organisasi, dalam berbagai ukuran, penguasaan teknologi, tingkat kompleksitas dan formalisasi, didesain untuk terlibat dalam sistem penanganan informasi. ${ }^{8}$

\section{Komunikasi Horizontal dan Vertikal}

Secara garis besar, bentuk komunikasi organisasi terdiri atas: komunikasi vertikal (vertical communication) dan komunikasi horizontal (horizontal communication). Keduanya akan kita bahas di bawah ini.

\section{Komunikasi vertikal}

Komunikasi vertikal (vertical communication) mencakup komunikasi organisasi aliran ke bawah atau downward communication maupun aliran ke atas atau upward communication. Kita akan menjelaskan keduanya di bawah ini.

a. Komunikasi aliran ke bawah (Downward communication): terdapat lima elemen dari komunikasi aliran ke bawah. Elemen Pertama adalah perintah-perintah kerja yang umum 
dan sederhana yang disampaikan kepada bawahan melalui permintaan langsung (direct orders), waktu pelatihan (training sessions), deskripsi tugas (job descriptions), dan mekanisme lainnya. Tujuan dari instruksi kerja adalah untuk memastikan kepercayaan dan konsistensi prestasi kerja. Untuk pekerjaan yang tidak pasti dan lebih kompleks dibutuhkan instruksi yang lebih umum. Elemen kedua rasionalisasi tugas dan hubungannya dengan misi organisasi. Filosofi organiasi akan menentukan berapa banyak informasi yang dikomunikasikan. Jika filosofinya untuk menjaga anggota organisasi tetap bahagia, sedikit informasi yang akan dikomunikasikan. Organisasi menganggap bahwa daripada memberikan terlalu banyak informasi yang tidak bisa ditangani oleh anggota, maka diperkenalkan berbagai variasi ke dalam pekerjaan yang akan ditanganinya. Elemen ketiga adalah informasi ditentukan oleh prosedur dan praktek di dalam organisasi. Seperti pada elemen pertama (instruksi kerja), secara relatif langsung diterima dan tidak bersifat kontroversi. Di sini, apakah terkait dengan elemen kedua atau tidak, merupakan sebuah masalah. Umpan balik kepada individual tergantung pada kinerja adalah elemen keempat dari sistem komunikasi aliran ke bawah. Di sini hampir dibatasi oleh isu khususnya ketika umpan balik itu negatif. Jika isu itu terkait dengan sosio-emosinal dari bawahan, maka isu itu menjadi lebih sulit ditangani. Elemen keempat terkait dengan upaya indoktinasi bawahan ke dalam misi dan kepercayaan organisasi. Maksudnya bahwa perlu mendapatkan personel secara emosional yang terkait dengan pekerjaan mereka dan menambahkan sistem motivasional.

b. Komunikasi aliran ke atas (Upward communication): berbeda dengan hukum gravitasi, komunikasi dalam organisasi juga mesti naik ke atas. Katz dan Kahn (1978) mengatakan bahwa: komunikasi ke atas muncul dalam beberapa bentuk, ketika anggota mengatakan atau menyampaikan laporan kepada pimpinan tentang: (1) diri mereka, kinerja mereka, dan masalah mereka; (2) tentang hal lain dan masalah mereka; (3) tentang praktek dan kebijakan organisasi; dan (4) apa yang dilakukan dan bagaimana melakukannya. Anggota tidak menyukai untuk menyampaikan informasi ke atas jika hal itu terlarang untuk mereka sendiri atau kelompoknya. Dengan demikian, jumlah dan jenis informasi yang disampaikan ke atas sesauai dengan khirarki. Setiap orang dalam berbagai organisasi mengetahui bahwa berdiskusi dengan direktur, kepala bagian, direktur, supervisor, dan sebagainya akan menjadi hambatan sesuai dengan kekuatan superior yang dimiliki organisasi.

Wajah lain dari komunikasi aliran ke atas yang penting adalah: ketika komunikasi ke bawah lebih mendetail dan spesifik, maka komunikasi ke atas harus lebih padat dan terangkum. Bagian tengah dari organisasi akan melakukan filter dan editing informasi. Hanya informasi-informasi yang krusial yang diijinkan untuk sampai ke level puncak.

\section{Komunikasi horizontal}

Komunikasi di dalam organisasi tidak hanya ke arah atas dan bawah. Komunikasi horizontal atau lateral merupakan sisi reguler dan penting dalam kehidupan organisasi. 
Fokus dari sebagian besar analis komunikasi adalah axis vertikal. Komponen horizointal kurang mendapatkan perhatian, walaupun proporsi yang besar dari komunikasi ini muncul di dalam organisasi sebagai sebuah tipe. Studi pada sebuah pabrik tekstil menunjukkan bahwa level yang lebih rendah di dalam khirarki, menunjukkan proporsi komunikasi horizontal yang lebih besar. Hal ini bukan suatu kejutan, bahwa orang-orang lebih senang berkomunikasi dengan sesamanya (level yang sama) di dalam organisasi.

Komunikasi dengan sesama level lebih disukai karena memiliki kesamaan karakteristik antara pihak-pihak yang terlibat dalam komunikasi horizantal.

Komunikasi di dalam suatu subunit sangat berbeda dengan komunikasi antar subunit. Komunikasi di dalam unit adalah faktor yang sangat menentukan efektivitas fungsi sistem.

Dalam sebagian besar kasus, tidak mungkin sebuah organisasi dapat bekerja optimal tanpa komunikasi antara anggota dengan anggota lainnya. Interaksi antara anggota dengan anggota hanyalah satu bentuk dari komunikasi horizontal. Bentuk lainnya muncul ketika terjadi komunikasi anggota subunit berbeda. Karena itu, komunikasi horizaontal perlu diarahkan untuk mencapai tujuan-tujuan organisasi secara efektif. ${ }^{9}$

Seperti halnya dalam komunikasi kelompok, potensi komunikasi organisaasi tidak dapat diremehkan. Semakin banyak anggota yang terlibat, maka jumlah jaringan komunikasi (linkage) yang terbentuk juga makin besar, bahkan meningkat secara eksponensial. Jaringan muncul ketika individu-individu bertemu dan mereka berbagi antara satu dengan lainnya. Jaringan komunikasi organisasi segera terbentuk ketika setiap anggota berpartisipasi dalam setiap interaksi, baik secara vertikal maupun horizontal.

\section{Komunikasi Berbasis Elektronik}

Komunikasi organisasi dapat dilakukan secara langsung (non media) atau memanfaatkan media elektronik. Tidak semua aktivitas komunikasi organisasi dapat dilakukan secara tatap muka, maka mediasi teknologi elektronik sangat diperlukan. Pemanfaatan jaringan elektronik sangat membantu pembentukan organisasi yang solid dan efektif untuk mencapai tujuannya. Adanya kendala ruang dan waktu dalam komunikasi organisasi, dapat diatasi dengan hadirnya teknologi yang memediasi. Karena melibatkan teknologi media, maka komunikasi organisasi tidak lagi sekadar perpanjangan dari komunikasi interpersonal. Penelitian maupun pengembangan teknologi untuk komunikasi kelompok terus berkembang beberapa tahun belakangan. Bahkan teknologi komunikasi, baik dari segi hardware, software maupun network, terus dikembangkan oleh vendor atau perusahaan sebagai ladang bisnis yang sangat menjanjikan untuk melayani organisasiorganisasi di seluruh dunia.

Network (jaringan elektronik) merupakan suatu kumpulan komputer otonom yang saling berhubungan dengan teknologi tunggal. Dua komputer dikatakan saling berhubungan jika mereka dapat saling bertukar informasi. Sambungan tidak perlu melalui kawat tembaga, 
serat optik, microwave, inframerah, dan satelit komunikasi juga dapat digunakan. Jaringan datang dalam berbagai ukuran, bentuk dan bentuk, seperti yang akan kita jelaskan nanti. Mereka biasanya terhubung bersama-sama untuk membuat jaringan yang lebih besar, dengan Internet menjadi contoh yang paling terkenal dari jaringan yang kompleks.

Ada kebingungan yang sering ditemukan dalam literatur antara jaringan komputer ( $a$ computer network) dan sistem terdistribusi (a distributed system). Kunci perbedaan adalah bahwa dalam sistem terdistribusi, merupakan kumpulan komputer independen di mana penggunanya sebagai sistem tunggal yang koheren. Biasanya, ia memiliki model tunggal atau paradigma yang menyajikan kepada pengguna. Seringkali lapisan perangkat lunak di atas sistem operasi, middleware disebut, bertanggung jawab untuk melaksanakan model ini. Sebuah contoh yang terkenal dari suatu sistem terdistribusi adalah World Wide Web. Sistem ini berjalan di atas Internet dan menyajikan model di mana semuanya terlihat seperti dokumen (halaman Web). Sementara dalam sebuah jaringan komputer, tidak ada suatu model dan satu software. Pengguna memilih sistem dan bertindak dengan cara yang koheren. Jika mesin memiliki hardware yang berbeda dan sistem operasi yang berbeda, yang sangat transparan kepada pengguna. Jika seorang pengguna ingin menjalankan program pada mesin remote, ia harus masuk ke mesin itu dan menjalankannya di sana. Akibatnya, sebuah sistem terdistribusi adalah suatu sistem perangkat lunak yang dibangun di atas jaringan. Perangkat lunak ini memberikan keterpaduan dan transparansi. Dengan demikian, perbedaan antara jaringan dan sistem terdistribusi terletak pada perangkat lunak (sistem operasi), bukan dengan perangkat keras. $^{10}$

Untuk perusahaan kecil, semua komputer cenderung berada dalam satu kantor atau mungkin bangunan tunggal, tapi untuk yang lebih besar, komputer dan karyawan dapat tersebar di puluhan kantor. Namun demikian, bagian penjualan di New York mungkin kadang-kadang perlu akses ke database persediaan produk di Singapura. Konsep jaringan merupakan upaya untuk mengakhiri tirani "geografi" akan kendala ruang dan waktu. Dalam istilah sederhana, seseorang dapat membayangkan sistem informasi perusahaan sebagai terdiri dari satu atau lebih database dengan informasi perusahaan dan beberapa jumlah karyawan yang perlu mengakses mereka dari jarak jauh. Dalam model ini, data yang disimpan pada komputer kuat yang disebut server. Sering kali ini terpusat disimpan dan dipelihara oleh administrator sistem. Sebaliknya, karyawan memiliki mesin sederhana yang disebut klien di meja mereka sehingga mereka dapat mengakses data jarak jauh. Mesin-mesin klien dan server terhubung dengan jaringan (gambar 2). Perhatikan bahwa kita telah menunjukkan jaringan sebagai oval yang sederhana, tanpa detail apapun. 
Gambar 2.

Klien, jaringan dan server

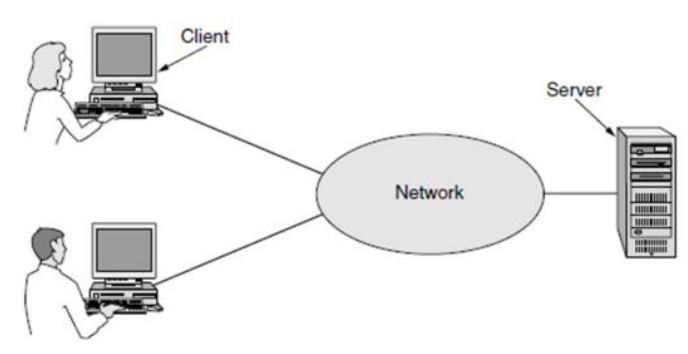

Sumber: Tanenbaum and Wetherall (2011:4)

Komunikasi berwahana komputer (computer-mediated communication) merupakan salah satu bidang yang penting dan cukup baru dalam komunikasi organisasi. Harusi diakui bahwa penggunaan teknologi komputer dengan berbagai aplikasinya di bidang komunikasi dan informasi telah mengubah cara berinteraksi bagi orang-orang yang ada di dalam satu organisasi maupun antar organisasi. Penggunaan itu mencakup sistem obrolan (chatting) diadik secara real time seperti instant massenger, konferensi, serta game permainan peran, dan sistem pendukung keputusan organisasi yang bisa diubah-ubah. Ini juga mencakup sistemsistem tanpa unsur keserempakan semisal papan buletin diadik atau e-mail berbasais daftar dan papan buletin terdistribusi dan sistem-sistem diskusi. Ia juga mencakup world wide web, termasuk sistem tekstual, grafis, fotografi, audio, dan vide, di dalam sejumlan sistem berbagai video seperti youtube, situs jejaring sosial, sistem pncarian pertemanan seperti mySpace dan facebook, bisa juga mencakup ruang interaksi sosial dengan perlengkapan grafis berbasis komputer seperti second life atau sejumlah permainan peran berpemain banyak seperti MMORPG dan massively multiplayer online role-playing game. ${ }^{11}$

Komunikasi organisasi berbasis elektronik dapat berupa: Personal Area Network (PAN) atau jaringan area pribadi; Local Area Network (LAN) atat jaringan area lokal; Metropolitan Area Network (MAN) atau jaringan area metropolitan; dan Wide Area Network (WAN) atau jaringan area luas.

\section{Personal Area Network (PAN)}

Jaringan yang paling kecil ruang lingkupnya adalah PAN (Personal Area Network), dimana seorang pengguna memakai beberapa perangkat pribadi dalam satu jaringan kerja, seperti PC yang terhubungan dengan printer, LCD, dan speaker. Personal Area Network atau Jaringan area pribadi (PAN) adalah sebuah jaringan komputer yang digunakan untuk komunikasi antara perangkat komputer, termasuk telepon dan personal digital assistant, yang berada di dekat seseorang. 


\section{Local Area Network (LAN)}

Jaringan yang lebih besar setelah PAN adalah LAN (Local Area Network), yaitu jaringan komputer dalam satu gedung atau antar gedung yang masih berada dalam jarak sekitar 50 meter. LAN biasanya dimiliki oleh suatu organisasi untuk menghubungkan satu bagian dengan bagian lain di dalam organisasi itu. Sebuah jaringan area lokal (LAN) menghubungkan komputer di daerah terbatas seperti rumah, sekolah, laboratorium komputer atau gedung kantor.

\section{Metropolitan Area Network (MAN)}

Kemudian MAN (Metropolitan Area Network), yaitu jaringan antar gedung, instansi, kantor, perusahaan, dalam satu kota atau antar kota. Metropolitan Area Network mencakup area metropolitan atau kampus. Cakupan geografis yang jatuh antara WAN dan LAN. MAN menyediakan konektivitas Internet untuk LAN di wilayah metropolitan dan menghubungkan mereka ke jaringan area yang lebih luas seperti WAN atau Internet (international networking).

\section{Wide Area Network (WAN)}

Terakhir, jaringan yang paling besar adalah WAN (Wide Area Network) yang mencakup hubungan antar negara, benua, atau global. Internet (international networking) merupakan salah satu perwujudan dari WAN. Sebagai contoh, banyak perusahaan multinasional menggunakan WAN untuk mengirim dan menerima informasi diantara pekerja mereka, konsumen, suplier, atau organisasi lain melintasi kota, bangsa, negara, dan dunia. Setiap bentuk jaringan (network) ini dapat terhubung baik melalui kabel (fisik) atau nirkabel (frekuensi / gelombang radio). Sebuah jaringan area luas (WAN) adalah jaringan telekomunikasi yang mencakup area yang luas (yaitu, jaringan apapun yang menghubungkan seluruh metropolitan, regional, atau batas-batas nasional). Entitas bisnis dan pemerintah memanfaatkan WAN untuk relay data antara karyawan, klien, pembeli, dan pemasok dari berbagai lokasi geografis. Pada dasarnya telekomunikasi mode ini memungkinkan bisnis untuk secara efektif melaksanakan fungsi sehari-hari terlepas dari lokasi di mana pun ia berada. Hal ini berbeda dengan jaringan area pribadi (PAN), jaringan area lokal (LAN), jaringan area metropolitan (MAN) yang terbatas pada sebuah ruangan, gedung, kampus atau wilayah metropolitan tertentu (misalnya sebuah kota). Namun WAN menghubungkan siapa pun ke dalam jaringan negara, benua, bahkan global. ${ }^{13}$

Dengan bantuan teknologi elektronik, baik berupa hardware, software, dan network, maka suatu organisasi dapat lebih efektif dan efisien dalam mencapai tujuannya. Selain itu, melalui jaringan elektronik, maka organisasi dapat melayani publik tanpa dibatasi oleh waktu dan tempat, sehingga tujuan organisasi dapat lebih mudah terwujud. Pemimpin-pemimpin organisasi sudah saatnya menggunakan teknologi elektronik dalam mengembangkan kekuatan organisasi untuk merespon perubahan lingkungan yang berlangsung begitu cepat dan kompleks, seperti yang dialami saat ini dan di masa depan. 


\section{SIMPULAN}

Sebuah organisasi memerlukan komunikasi berbasis elektronik untuk menjalankan fungsinya dan mencapai tujuannya secara efektif. Organisasi tersebut mungkin memiliki komputer dan perangkat-perangkat elektronik untuk setiap pekerja dan menggunakannya untuk membuat desain produk, menulis brosur, mencetak daftar gaji, bertukar data antar bagian, atau melakukan konsultasi antara bahasan dengan pimpinan. Beberapa komputer ini bekerja secara terpisah dari orang lain, tetapi pada beberapa titik, jaringan elektronik dibutuhkan untuk menghubungkan mereka dan mendistribusikan informasi di seluruh organisasi. Tujuan utama penggunaan jaringan elektronik dalam organisasi adalah untuk berbagi sumberdaya fisik (hardware), program (software), jaringan (network) dan dan bertukar data antara satu pengguna dengan lainnya.

Sebagai contoh, sekelompok pekerja kantor berbagi printer yang sama. Tidak ada pekerja yang benar-benar membutuhkan printer pribadi khusus, dan menggunakan printer berjaringan biasanya lebih murah, lebih cepat, dan lebih mudah untuk mempertahankan daripada koleksi besar printer individu. Namun, bahkan lebih penting daripada berbagi sumber daya fisik seperti printer, dan sistem tape backup, adalah berbagi informasi. Organisasi kecil dan besar sangat tergantung pada informasi yang terkomputerisasi. Sebagian besar organisasi bisnis memiliki data pelanggan, informasi produk, persediaan, laporan keuangan, pajak, informasi, dan banyak lagi online. Jika semua komputer yang menyimpan data, tiba-tiba offline, sebuah bank tidak bisa melayani nasabahnya. Sebuah pabrik manufaktur modern dengan jalur perakitan dikendalikan komputer, tidak akan menghasilkan produk kalau komputernya mengalami gangguan. Sebuah firma hukum kecil sekarang sangat tergantung pada jaringan komputer untuk memungkinkan karyawan untuk mengakses dokumen yang relevan.

Dengan demikian keberadaan teknologi elektronik dan komputer sangat menentukan kesukesan sebuah organisasi, terutama dalam membangun kerjasama dan interaksi antara setiap tenaga kerja sehingga tujuan organisasi lebih mudah terwujud. Organisasi bisa tetap tumbuh dan berkembang bila mempu merespon perkembangan yang ada di sekitarnya, yaitu kemajuan teknologi komunikasi dan informasi yang telah menjadi ssalah satu perangkat penting dalam organisasi modern saat ini. Wallahu alam bis shawab.*** 


\section{Endnotes}

${ }^{1}$ Muhammad Anshar Akil, Ilmu Komunikasi: Konstruksi, Proses dan Level Komunikasi Kontemporer, (Makassar, Alauddin University Press, 2012), h.115

${ }^{2}$ T.E. Harris; and Mark D. Nelson, Applied Organizational Communication: Theory and Practice in a Global Environment, (Taylor \& Francis Group, LLC, New York 2008), p.19

${ }^{3}$ S. D. Sendjaja dkk. , Pengantar Komunikasi, (Universitas Terbuka, Jakarta 1999), h.39

${ }^{4}$ R. W. Pace; and Don F. Faules. Deddy Mulyana (editor), Komunikasi Organisasi: Strategi Meningkatkan Kinerja Perusahaan, (PT Remaja Rosdakarya, Bandung, 1998), h.3133

${ }^{5}$ Akil, Ilmu Komunikasi, 2012, h.117-118

${ }^{6}$ Akil, Ilmu Komunikasi, 2012, h.118

${ }^{7}$ J. Winardi, Manajemen Perilaku Organisasi, (Penerbit Kencana, Jakarta. 2007), h. 58

${ }^{8}$ Akil, Ilmu Komunikasi, 2012, h.119-120

${ }^{9}$ R.H. Hall; and Pamela S.Tolbert, Organizations: Structures, Processes, and Outcomes, (Pearson Education, Inc., New Jersey, 2005), pp.137-153

${ }^{10}$ Andrew S. Tanenbaum; and David J. Wetherall. 2011. Computer Networks, (Pearson Education, Inc., USA. 2011), p.3

${ }^{11}$ Charles R Berger; Michael E.Roloff; dan David R.Roskos-Ewoldsen, Handbook Ilmu Komunikasi (terjemahan), (Penerbit Nusa Media, Bandung, 2014), h.702

${ }^{12}$ Muhammad Anshar Akil, Teknologi Komunikasi dan Informasi: Tinjauan Sistem, Perangkat, Jaringan dan Dampak, (Penerbit Alauddin University Press, Makassar, 2011), h.165-174

\section{DAFTAR PUSTAKA}

Akil, Muhammad Anshar. 2011. Teknologi Komunikasi dan Informasi: Tinjauan Sistem, Perangkat, Jaringan dan Dampak. Penerbit Alauddin University Press, Makassar.

. 2012. Ilmu Komunikasi: Konstruksi, Proses dan Level Komunikasi Kontemporer. Alauddin University Press, Makassar.

Berger, Charles R; Michael E.Roloff; dan David R.Roskos-Ewoldsen. 2014. Handbook Ilmu Komunikasi. Penerbit Nusa Media, Bandung.

Hall, R. H. and Pamela S.Tolbert. 2005. Organizations: Structures, Processes, and Outcomes. Pearson Education, Inc., New Jersey.

Harris, T. E., and Mark D. Nelson. 2008. Applied Organizational Communication: Theory and Practice in a Global Environment. Taylor \& Francis Group, LLC, New York.

Pace, R. W. and Don F. Faules. Deddy Mulyana (editor). 1998. Komunikasi Organisasi: Strategi Meningkatkan Kinerja Perusahaan. PT Remaja Rosdakarya, Bandung. 
Jurnal Tabligh Edisi Desember 2016 : 73 - 84

Sendjaja, S. D., dkk. 1999. Pengantar Komunikasi. Universitas Terbuka, Jakarta.

Tanenbaum, Andrew S; David J. Wetherall. 2011. Computer Networks. Pearson Education, Inc., USA.

Winardi, J. 2007. Manajemen Perilaku Organisasi. Penerbit Kencana, Jakarta. 